\title{
Saraca indica bark extract mediated green synthesis of polyshaped gold nanoparticles and its application in catalytic reduction
}

\author{
Shib Shankar Dash • Rakhi Majumdar • \\ Arun Kanti Sikder • Braja Gopal Bag • \\ Biplab Kumar Patra
}

Received: 15 January 2013/Accepted: 3 April 2013/Published online: 20 April 2013

(c) The Author(s) 2013. This article is published with open access at Springerlink.com

\begin{abstract}
The bark extract of the traditional ayurvedic medicinal plant Saraca indica containing redox active polyphenolic compounds has been utilized for the one-step synthesis of gold nanoparticles at room temperature. The polyphenolic compounds acted as the reducing agent as well as the stabilizing agent without any additional capping agent. The synthesis of the gold nanoparticles of 15-23 nm size was complete in several minutes and no photo irradiation or heat treatment was necessary. Surface plasmon resonance, HRTEM, AFM, X-ray diffraction, and FTIR studies have been carried out to characterize the nanoparticles. Gold nanoparticles synthesized were of triangular, tetragonal, pentagonal, hexagonal, and spherical shapes. The synthesized gold nanoparticles have been used as a catalyst for the reduction of 4-nitrophenol to 4-aminophenol at room temperature and the kinetics of the reduction reaction has been studied spectrophotometrically.
\end{abstract}

Keywords Green synthesis - Gold nanoparticles . Catalytic reduction $\cdot$ Saraca indica $\cdot$ Polyphenol

Electronic supplementary material The online version of this article (doi:10.1007/s13204-013-0223-z) contains supplementary material, which is available to authorized users.

S. S. Dash · R. Majumdar · B. G. Bag $(\bowtie)$ B. K. Patra Department of Chemistry and Chemical Technology, Vidyasagar University, Midnapore 721 102, West Bengal, India e-mail: braja@mail.vidyasagar.ac.in

\section{A. K. Sikder}

High Energy Materials Research Laboratory (HEMRL), Defence Research and Development Organization (DRDO), Sutarwadi, Pune 411 021, India

\section{Introduction}

Gold nanoparticles (AuNPs) have attracted tremendous attention in recent years because of its unique optoelectronic properties and also because of its applications in catalysis, biotechnology, drug delivery (Jain et al. 2008) and biodiagnostics (Rosi and Mirkin 2005; Dykman and Khlebtsov 2012; Iravani 2011a, b; Judy et al. 2011), medicine and electronics (Brust et al. 1998; Tanaka 1999; McConnell et al. 2000; Troiani et al. 2003). AuNPs exhibit different colors depending upon its size, shape, and degree of aggregation and, hence, have been used as probes for the detection of heavy metal ions colorimetrically (Liu and $\mathrm{Lu}$ 2003). AuNPs have also been utilized as advanced building blocks for nanoscale self-assembled systems (Pankau et al. 2001; Christopher et al. 2011). Techniques for the synthesis of nanoparticles fall mainly under two main catagories: 'top-down' and 'bottom-up' (Kulkarni 2007). Although, there are many reports in the literature for the synthesis of AuNPs, most are time consuming or tedious (Kundu and Liang 2008; Zhou et al. 2007). Whereas, the chemical 'topdown' methods have the risk of environmental contaminations due to the generations of large amount of hazardous by-products, the bio-based 'bottom-up' approach provides an environmentally benign alternative for the generation of nanostructures with more homogeneous chemical compositions (Haynes and Nordle 1994; Ghosh and Pal 2009; Sinha et al. 2010). AuNPs have been successfully synthesized from Bayberry tannin and medicinally important alpha-alpha (Montes et al. 2011; Armendariz et al. 2004; Huang et al. 2010). During the course of our investigations with plant secondary metabolites as renewable chemicals (Bag et al. 2012, 2013; Bag and Dash 2011; Bag and Dinda 2007; Bag and Paul 2012; Bag and Majumdar 2012), it occurred to us that the polyphenolic compounds present in 
the bark extract of the Saraca indica can be utilized for the synthesis of AuNPs from gold tetrachloroaurate $\left(\mathrm{AuCl}_{4}{ }^{-}\right)$ (Sadhu et al. 2007; Indrani and Balasubramanian 1985a, 1985b; Middelkoop and Labadie 1985; Duggal and Misra 1980; Dash and Bag 2013, Majumdar and Bag 2012). Herein, we report a simple method for the synthesis of AuNPs utilizing the medicinally important $S$. indica bark extract without any additional capping agent. Our method for the synthesis of AuNPs, utilizing S. indica bark extract reported here, is more efficient or comparable to other reported methods in the literature utilizing plant extracts. The synthesized AuNPs have been characterized by highresolution transmission electron microscopy (HRTEM), atomic force microscopy (AFM), surface plasmon resonance spectroscopy, X-ray diffraction (XRD) and Fourier transform infrared (FTIR) studies. Catalytic application of the synthesized gold nanoparticles has been studied for the sodium borohydride reduction of 4-nitrophenol to 4-aminophenol and the catalytic rate constants have been determined spectrophotometrically.

\section{Experimental}

Synthesis and characterization of gold nanoparticles

$\mathrm{HAuCl}_{4}$ was purchased from SRL (Sisco Research Laboratory) and used without further purification. $\mathrm{HAuCl}_{4}$ (35.4 mg) was dissolved in deionized water $(10 \mathrm{~mL})$ to obtain a $10.42 \mathrm{mM} \mathrm{Au(III)} \mathrm{stock} \mathrm{solution.} \mathrm{Aliquots} \mathrm{of}$ $\mathrm{Au}$ (III) solution $(0.16 \mathrm{~mL}, 10.42 \mathrm{mM}$ each) were added dropwise to the bark extract solution (containing polyhydroxy aromatic compounds) to prepare a series of stabilized AuNPs where concentration of the bark extract varies from 20 to $200 \mathrm{mg} \mathrm{L}^{-1}$ and the concentration of $\mathrm{Au}(\mathrm{III})$ was fixed at $0.42 \mathrm{mM}$. UV-visible measurements of the solutions were carried out $30 \mathrm{~min}$ after $\mathrm{HAuCl}_{4}$ and $S$. indica bark extract were mixed together. TEM images of AuNPs were recorded in JEOL JEM-2100 instrument. AFM was carried out in Vecco dicp II Model no. AP0100. XRD patterns of the stabilized AuNPs were recorded in Rigaku Miniflex II diffractometer with $\mathrm{Cu}-\mathrm{K} \alpha$ radiation $(\lambda=1.54 \AA$ ̊). Mass spectra were recorded in Shimadzu GCMS QP 2100 Plus. UV-visible spectra were recorded in Shimadzu 1601 spectrophotometer. FTIR spectra of the samples were analyzed using a Perkin-Elmer Spectrum 2 instrument at a resolution of $1 \mathrm{~cm}^{-1}$.

\section{Results and discussion}

The bark extract of $S$. indica contains several compounds containing multiple phenolic hydroxyl groups, such as quercetin, (-) epicatechin, (+) catechin, leucopelargonidin-3-O-p-D-glucoside, leucopelargonidin, gallic acid, leucocyanidin, etc. (supporting information Fig. S1) (Sadhu et al. 2007). The $o$-dihydroxyl groups can easily form five-member chelate ring and also be oxidized to the corresponding benzoquinones either by air or by metal ions. Thus, these phenolic hydroxyl containing compounds can be used as an effective reducing agent for $\mathrm{Au}(\mathrm{III})$ which has a high oxidation-reduction potential (Ferrer et al. 1999). The $\mathrm{Au}(0)$ thus formed may collide with the neighboring $\mathrm{Au}(0)$ atoms forming $\mathrm{Au}$ nanoparticles and get stabilized by the concomitantly generated benzoquinone derivatives (Kim and Nakano 2005). To test this, we treated aqueous $\mathrm{HAuCl}_{4}$ solutions with increasing concentration of the bark extract of $S$. indica. Interestingly, we observed the appearance of pinkish red coloration almost instantly indicating the formation of AuNPs. The intensity of the color increased on standing the solution at room temperature for several hours (Fig. 1).

UV-visible spectroscopy studies

Due to charge transfer interactions between the metal and the chloro ligands, a strong absorption peak at $220 \mathrm{~nm}$ and

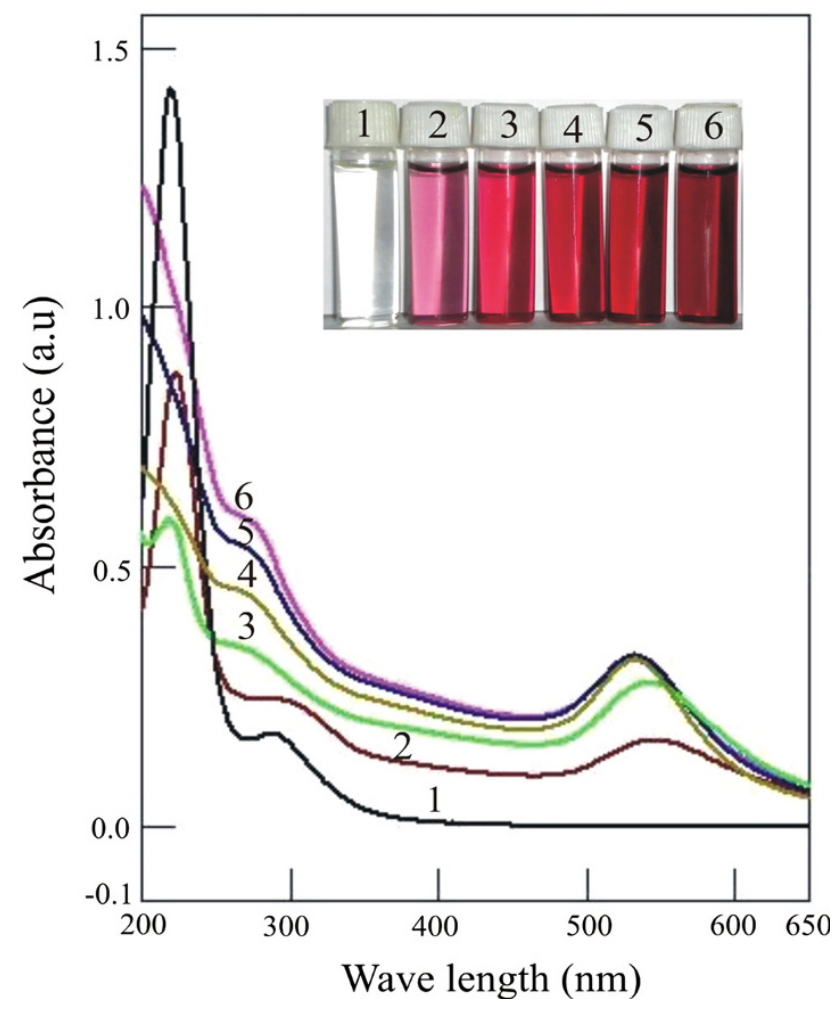

Fig. 1 UV-visible spectra of (1) $\mathrm{HAuCl}_{4}(0.42 \mathrm{mM}),(2-6)$ AuNP's at $20,40,60,80,100 \mathrm{mg} \mathrm{L}^{-1}$ concentrations of Saraca indica bark extract, respectively. Inset photograph of the vials containing the solutions (after $24 \mathrm{~h}$ of mixing) 

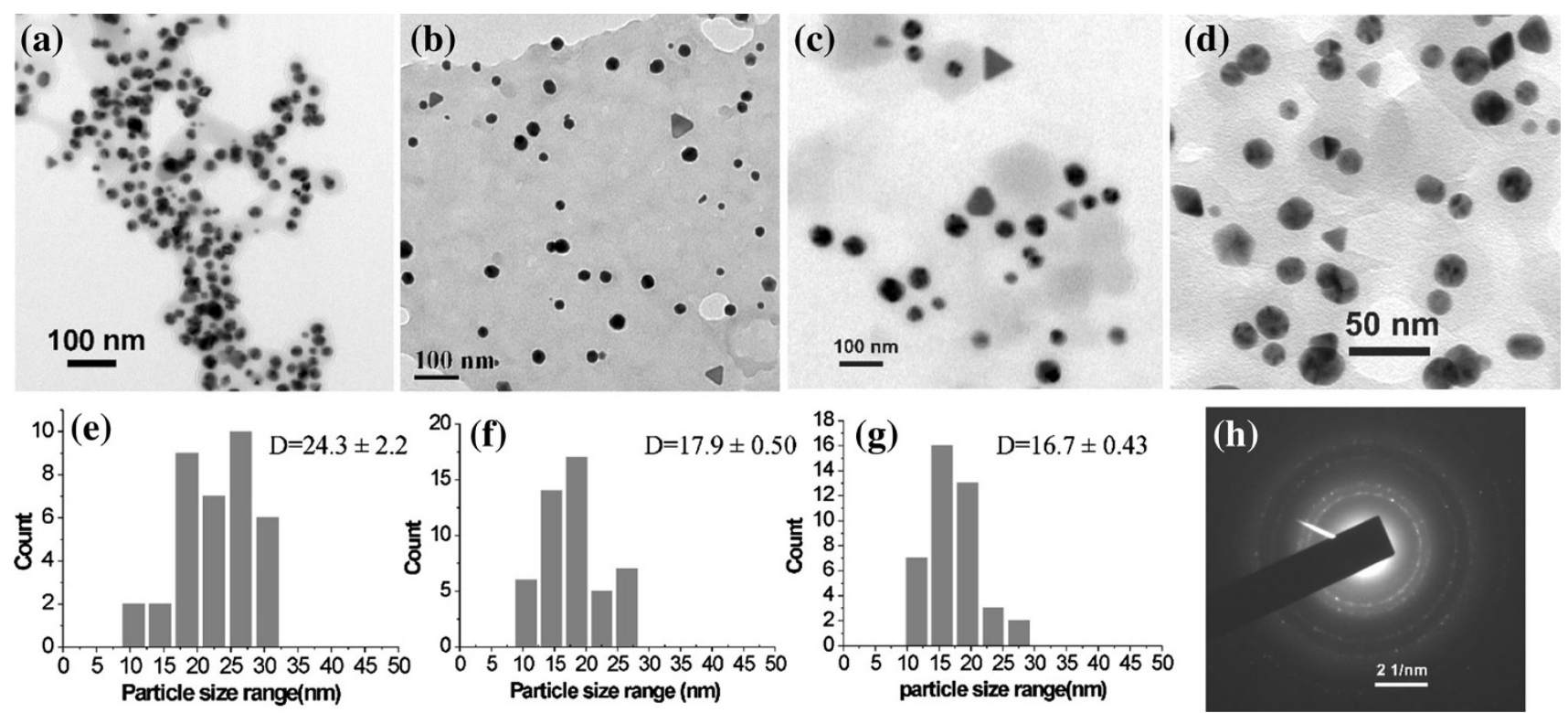

Fig. 2 a-d TEM images of AuNPs obtained with Saraca indica bark extract at 80, 100, 120, and $200 \mathrm{mg} \mathrm{L}^{-1}$ concentration, respectively; eg histograms are for the AuNPs at 100,120 , and $200 \mathrm{mg} \mathrm{L}^{-1}$ of the bark extract. $D$ mean particle diameter, h SAED image of AuNPs

a shoulder peak at $290 \mathrm{~nm}$ were observed in the UV-visible spectrum of $\mathrm{HAuCl}_{4}$ (Fig. 1). With increasing concentration of the $S$. indica bark extract, the intensities of these peaks decreased and new peaks in the region of 530-570 nm appeared due to surface plasmon resonance (SPR) of the AuNPs (Esumi et al. 2000). A blue shift of the SPR band was observed from 570 to $530 \mathrm{~nm}$ with increasing concentration of the bark extract from 20 to $80 \mathrm{mg} \mathrm{L}^{-1}$. This blue shift is perhaps due to the formation of more stabilized, smaller-sized nanoparticles with increasing concentration of the $S$. indica bark extract. Above $100 \mathrm{mg} \mathrm{L}^{-1}$ concentration of the bark extract, the intensity of the SPR band did not increase further on increasing the extract concentration perhaps due to complete reduction of the accessible $\mathrm{Au}(\mathrm{III})$ to $\mathrm{Au}(0)$ (Huang et al. 2010). A broad peak at 270-275 $\mathrm{nm}$ region observed in the case of AuNPs might be due to the quinone moiety resulting from the oxidation of phenolic compounds.

\section{HRTEM, EDX, FTIR, XRD, and AFM studies}

The morphologies of the AuNPs obtained at different concentration of the $S$. indica bark extract were studied by Transmission Electron Microscopy. The size of the nanoparticles formed at various concentrations of the $S$. indica bark extract is shown in Fig. 2 (and supporting information Fig. S3 and S4). The average size of the AuNPs showed a gradual decrease from 23 to $15 \mathrm{~nm}$ when the concentration of the bark extract increased from 80 to $200 \mathrm{mg} \mathrm{L}^{-1}$ that is consistent with the blue shift observed in the SPR bands (Fig. 1). Nanoparticles were of different shapes such as triangular, pentagonal, hexagonal, and spherical (Fig. 2). The gold nanoparticles were so stable that no further aggregation took place on standing the solutions for several months. Selected area electron diffraction (SAED) image (Fig. 2h) and energy disperse X-ray (EDX) spectrum (supporting information Fig. S5) confirmed the formation of AuNPs.

We have compared the FTIR spectra of $S$. indica bark extract and stabilized AuNPs (Fig. 3). The broad peak in the 3,600-3,200 $\mathrm{cm}^{-1}$ region of the FTIR spectrum of bark extract is due to stretching vibration of the intermolecularly hydrogen-bonded phenolic hydroxyl groups. The 1,612, $1,517,1,444 \mathrm{~cm}^{-1}$ peaks are due to the presence of aromatic rings in the extract. In the FTIR spectrum of the $S$. indica extract stabilized AuNPs, the absorption peak for the phenolic hydroxyl groups became narrower. This is due to the interaction of phenolic hydroxyl groups with AuNPs with concomitant weakening of H-bonding among the

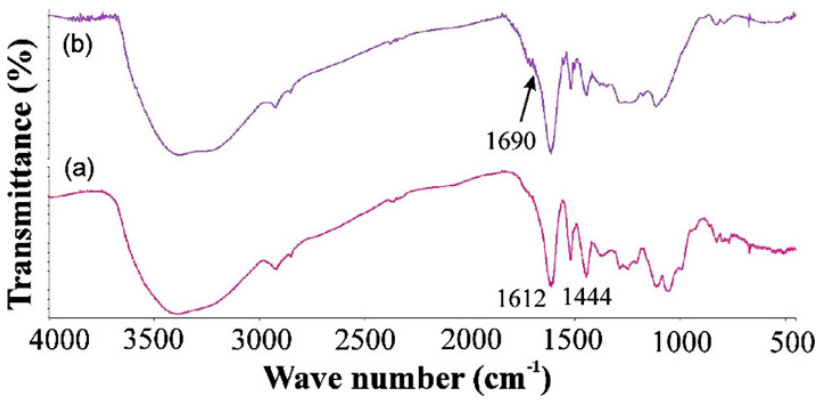

Fig. 3 FTIR (KBr) Spectrum of a Saraca indica bark extract; b stabilized AuNPs; the arrow indicates the presence of carbonyls due to the formation of quinones in the AuNPs 
phenolic hydroxyl groups. The appearance of newer peaks around $1,690 \mathrm{~cm}^{-1}$ in the FTIR of AuNPs indicated the formation of quinones.

The crystalline nature of the metallic face-centered cubic gold nanoparticles was confirmed from the intense peaks in the XRD pattern of gold nanoparticles $\left[2 \theta=38.3^{\circ}, 44.3^{\circ}\right.$, $64.8^{\circ}$, and $77.9^{\circ}$ corresponding to planes (111), (200), (220), and (311), respectively] (see supporting information Fig. S6 for details). These values agreed well with the reported standards JCPDS file no. 04-0784.

The morphology of the stabilized AuNPs was also studied by AFM (supporting information, Fig. S7). It is evident from the images that most of the particles are triangular and spherical shaped. The surface of the AuNPs observed by AFM contains high concentration of organic moieties along with the stabilized AuNPs. The presence of the organic matrix is also evident from TEM images (supporting information Fig. S4).

\section{Mechanism of the formation of stabilized AuNPs}

The bark of $S$. indica is rich in different types of medicinally important compounds containing multiple phenolic hydroxyl groups such as quercetin, $(-)$ epicatechin, $(+)$ catechin, leucopelargonidin-3-O-p-D-glucoside, leucopelargonidin, gallic acid, leucocyanidin, etc. (supporting information Fig. S1). Mass spectral analysis carried out by us also indicated the presence of most of the above polyphenolic compounds (supporting information Fig. S2). Taking quercetin as a representative of the $o$-dihydroxyphenolic compounds, a schematic representation of the possible mechanism for the synthesis of stabilized AuNPs is shown in Fig. 4. A five-member chelate ring can form from the $o$-dihydroxy groups of the polyphenolic compounds with $\mathrm{Au}(\mathrm{III})$ ion. Reduction of the chelated $\mathrm{Au}(\mathrm{III})$ ions to $\mathrm{Au}(0)$ takes place with concomitant oxidation of the ortho-hydroxyl groups to quinones. Neighboring $\mathrm{Au}(0)$ atoms collide with each other forming AuNPs which are then stabilized by the polyphenolic compounds as well as quinones (Huang et al. 2010).

Study of the catalytic activity of stabilized AuNPs

To study the catalytic activity of the synthesized AuNPs, the reduction of 4-nitrophenol to 4-aminophenol in the presence of $\mathrm{NaBH}_{4}$ was studied as a model reaction. In our study, $0.2 \mathrm{~mL}$ of 4-nitrophenol $(0.05 \mathrm{mM}), 3.6 \mathrm{~mL} \mathrm{NaBH}_{4}$ $(15 \mathrm{mM})$ and $0.2 \mathrm{~mL}$ of distilled water were mixed together and UV-visible spectra were taken. The absorption peak at $318.5 \mathrm{~nm}$ for 4-nitrophenol shifted to $400 \mathrm{~nm}$ ( $A=0.949)$ due to the formation of 4-nitrophenolate ion. Even though the reduction of 4-nitrophenol to 4-aminophenol is a thermodynamically favorable reaction $\left(E_{0}\right.$ for 4-nitrophenol/4-aminophenol -0.76 and for $\mathrm{H}_{3} \mathrm{BO}_{3} / \mathrm{BH}_{4}{ }^{-}$ $-1.33 \mathrm{~V}$ ), no reduction took place on standing the reaction mixture for several days due to a large kinetic barrier for the reduction reaction. Interestingly, in the presence of $S$. indica bark stabilized AuNPs $\left(0.2 \mathrm{~mL}, 60 \mathrm{mg} \mathrm{L}^{-1}\right)$ the intensity of the absorption peak decreased immediately with a concomitant formation of a new peak at $295 \mathrm{~nm}$ region indicating the reduction of 4-nitrophenol to 4-aminophenol. The progress of the reaction was monitored by the UV-visible spectroscopy at different time intervals (Fig. 5). The absorption peak of 4-nitrophenolate ion (at $400 \mathrm{~nm}$ ) completely disappeared and the solution became almost colorless indicating the completion of reduction reaction. The UV-visible data at different time interval have been utilized for the determination of catalytic rate constant $(k)$. Since the concentration of $\mathrm{NaBH}_{4}$ greatly exceeds the concentration of 4-nitrophenol, the reaction rate can be assumed to be pseudo first order. From the plot of $\ln \mathrm{A}$ vs time, the rate constant for the reduction reaction was calculated to be $0.25 \mathrm{~min}^{-1}$ (supporting information Fig. S8). In the presence of $0.3 \mathrm{~mL}$ of the stabilized AuNP

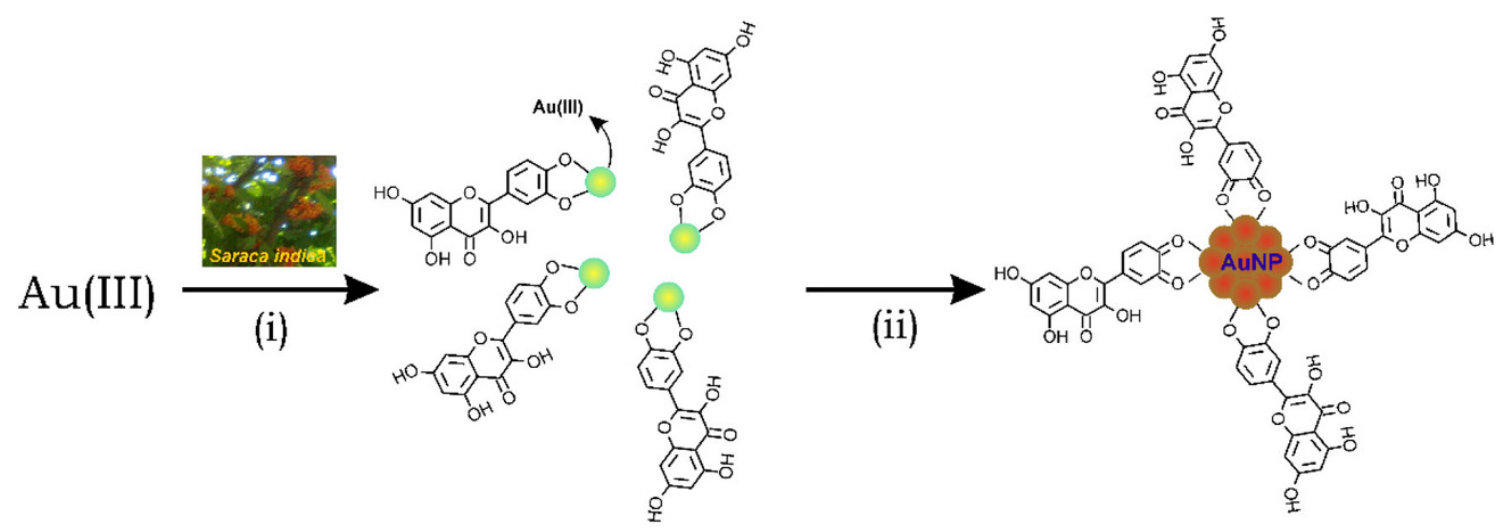

Fig. 4 Mechanism of the formation and stabilization of AuNPs by polyphenolic compounds present in Saraca indica bark extract: (i) Saraca indica bark extract containing polyphenolic compounds, (ii) auto reduction and stabilization of nanoparticles by the polyphenolic compounds 
Fig. 5 UV-visible spectra at different time interval during catalytic reduction of

4-nitrophenol to 4-aminophenol, a using $0.2 \mathrm{~mL}$ and $\mathbf{b} 0.3 \mathrm{~mL}$ of stabilized AuNPs

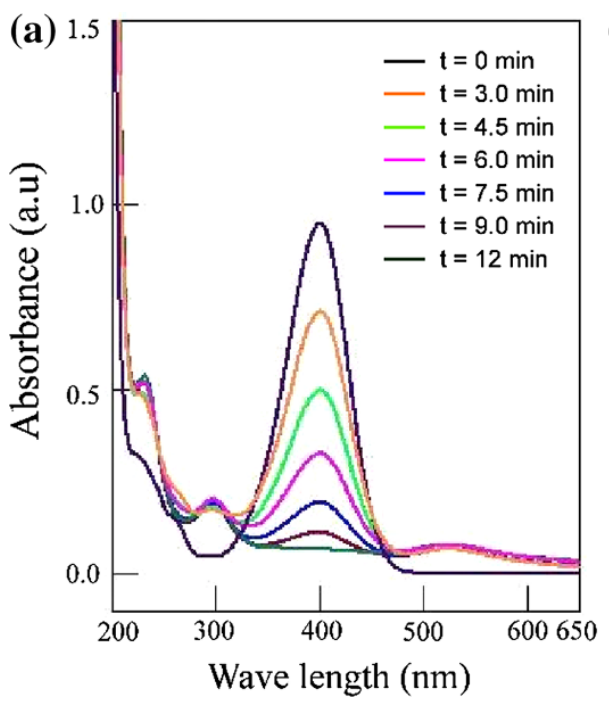

Table 1 Study of catalytic activities with variable amounts of AuNPs at $23^{\circ} \mathrm{C}$

\begin{tabular}{llll}
\hline Serial no. & $\begin{array}{l}\text { Amount of AuNPs } \\
\left(60 \mathrm{mg} \mathrm{L}{ }^{-1} \text { bark }\right. \\
\text { extract })(\mathrm{mL})\end{array}$ & $\begin{array}{l}\text { Time for } \\
\text { completion of } \\
\text { reaction }(\mathrm{min})\end{array}$ & $\begin{array}{l}\text { Catalytic rate } \\
\text { constant } \\
(k)\left(\mathrm{min}^{-1}\right)\end{array}$ \\
\hline 1 & 0.2 & 12 & 0.25 \\
2 & 0.3 & 9 & 0.29 \\
\hline
\end{tabular}

solution $\left(60 \mathrm{mg} \mathrm{L}^{-1}\right)$, the rate constant was calculated to be $0.29 \mathrm{~min}^{-1}$ (Table 1). The higher value of rate constant observed with larger volume of AuNP solution was due to more number of reaction sites (Gangula et al. 2011). The rate constant values were comparable to the values observed by us previously (Dash and Bag 2013) and others (Gangula et al. 2011) on similar systems.

\section{Conclusion}

We have demonstrated an extremely simple and efficient method for the green synthesis of gold nano particles using the bark extract of $S$. indica. The polyphenolic compounds present in the bark extract acts as an effective reducing agent for the reduction of $\mathrm{Au}(\mathrm{III})$ to $\mathrm{Au}(0)$ and no additional capping agent or stabilizer were necessary for the synthesis of stabilized gold nanoparticles. By increasing the concentration of the bark extract, smaller-sized polyshaped gold nanoparticles were obtained which has been supported by UV-visible spectroscopy and transmission electron microscopy. Room temperature reduction of 4-nitrophenol to 4-aminophenol has been achieved by the use of synthesized gold nanoparticles as a catalyst and the efficacy of the catalysts has been studied using spectrophotometric kinetic studies. As S. indica is used in ayurvedic medicine, the results described here will be useful for its application in medicine as well as other areas of nano research.

Acknowledgments BGB thanks DRDO for funding. RM and SSD thank UGC and CSIR, New Delhi for research fellowships.

Open Access This article is distributed under the terms of the Creative Commons Attribution License which permits any use, distribution, and reproduction in any medium, provided the original author(s) and the source are credited.

\section{References}

Armendariz V, Herrera I, Peralta-Videa JR, Yacaman JM, Troiani H (2004) Size controlled gold nanoparticle formation by Avena sativa biomass: use of plants in nanobiotechnology. J Nanopart Res 6:377-382

Bag BG, Dash SS (2011) First self-assembly study of betulinic acid, a renewable nano-sized, 6-6-6-6-5 pentacyclic monohydroxy triterpenic acid. Nanoscale 3:4564-4566

Bag BG, Dinda SK (2007) Arjunolic acid: a renewable template in supramolecular chemistry and nanoscience. Pure and Appl Chem 79:2031-2038

Bag BG, Majumdar R (2012) Self-assembly of a renewable nanosized triterpenoid $18 \beta$-glycyrrhetinic acid. RSC Advances 2:8623-8626

Bag BG, Paul K (2012) Vesicular and fibrillar gels by self-assembly of nanosized oleanolic acid. Asian J Org Chem 1:150-154

Bag BG, Garai C, Majumdar R, Laguerre M (2012) Natural triterpenoids as renewable nanos. Struct Chem 23:393-398

Bag BG, Majumdar R, Dinda SK, Dey PP, Maity GC, Mallia VA, Weiss RG (2013) Self-assembly of ketals of arjunolic acid into vesicles and fibers yielding gel-like dispersions. Langmuir 29:1766-1778

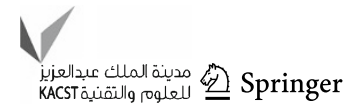


Brust M, Bethell D, Kiely CJ, Schiffrin DJ (1998) Self-assembled gold nanoparticle thin films with non-metallic optical and electronic properties. Langmuir 14:5425-5429

Christopher PS, Fernig DG, Levy R (2011) Gold nanoparticles as advanced building blocks for nanoscale self-assembled systems. J Mat Chem 21:12181-12187

Dash SS, Bag BG (2013) Synthesis of gold nanoparticles using renewable Punica granatum juice and study of its catalytic activity. Appl Nanosci. doi:10.1007/s13204-012-0179-4

Duggal JK, Misra K (1980) Leucoanthocyanidins from Saraca asoca stem bark. J Indian Chem Soc 57:1243

Dykman L, Khlebtsov N (2012) Gold nanoparticles in biomedical applications: recent advances and perspectives. Chem Soc Rev 41:2256-2282

Esumi K, Suzuki A, Yamahira A, Torigoe K (2000) Role of poly(amidoamine) dendrimers for preparing nanoparticles of gold, platinum, and silver. Langmuir 16:2604-2608

Ferrer M, Reina R, Rossell O, Seco M (1999) Anionic iron clusters as building blocks for the synthesis of higher nuclearity compounds containing 11- and 12-group elements Coordin. Coordin Chem Rev 193-5:619-642

Gangula A, Podila R, Ramakrishna M, Karanam L, Janardhana C, Rao AM (2011) Catalytic reduction of 4-nitrophenol using biogenic gold and silver nanoparticles derived from Breynia rhamnoides. Langmuir 27:15268-15274

Ghosh SK, Pal T (2009) Photophysical aspects of molecular probes near nanostructured gold surfaces. Phys Chem Chem Phys 11:3831-3844

Haynes CA, Nordle W (1994) Globular proteins at solid/liquid interfaces. Coll Surf B Biointerfaces 2:517-566

Huang X, Wu H, Liao X, Shia B (2010) One-step, size-controlled synthesis of gold nanoparticles at room temperature using plant tannin. Green Chem 12:395-399

Indrani N, Balasubramanian K (1985a) Isolation of condensed tannins from Saraca ashoka - part I. Leather Sci 31:349-350

Indrani N, Balasubramanian K (1985b) Isolation of condensed tannins from Saraca ashoka - part II. Leather Sci 32:12-13

Iravani S (2011a) Green synthesis of metal nanoparticles using plants. Green Chem 13:2638-2650

Iravani S (2011b) Green synthesis of metal nanoparticles using plants. J Am Chem Soc 125:6642-6643

Jain PK, Huang X, El-Sayed IH, El-Sayed MA (2008) Noble metals on the nanoscale: optical and photothermal properties and some applications in imaging, sensing, biology, and medicine. Acc Chem Res 41:1578-1586

Judy JD, Unrine JM, Bertsch PM (2011) Evidence for biomagnification of gold nanoparticles within a terrestrial food chain. Environ Sci Technol 45:776-781
Kim YH, Nakano Y (2005) Adsorption mechanism of palladium by redox within condensed-tannin gel. Water Res 39:1324-1330

Kulkarni SK (2007) Nanotechnology: principles and practices. Capital Publishing Company, New Delhi

Kundu S, Liang H (2008) Polyelectrolyte-mediated non-micellar synthesis of monodispersed 'aggregates' of gold nanoparticles using a microwave approach. Colloids Surf A 330:143-150

Liu JW, Lu Y (2003) A colorimetric lead biosensor using DNAzymedirected assembly of gold nanoparticles. J Am Chem Soc 125(22):6642-6643

McConnell WP, Novak JP, Brousseau LC III, Fuiere RR, Tenent RC, Feldheim DL (2000) Electronic and optical properties of chemically modified nanoparticles and molecularly bridged nanoparticle arrays. J Phys Chem B 104:8925-8930

Majumdar R, Bag BG (2012) Terminalia arjuna bark extract mediated size controlled synthesis of polyshaped gold nanoparticles and its application in catalysis Int J Res Chem. Environ 2:338-342

Middelkoop TB, Labadie RP (1985) The action of Saraca asoca Roxb. de Wilde bark on the PGH2 synthetase enzyme complex of the sheep vesicular gland. Z Naturforsch C 40:855-857

Montes MO, Maoral A, Deepak FL, Parsons JG, Yacaman JM, Peralta-Videa JR, Gardea-Torresdey JL (2011) Anisotropic gold nanoparticles and gold plates biosynthesis using alfalfa extracts. J Nanopart Res 13:3113-3121

Pankau WM, Verbist K, von Kiedrowski G (2001) Phase-transfer synthesis of novel water-soluble gold clusters with tripodal thioether based ligands. Chem Comm 6:519-520

Rosi NL, Mirkin CA (2005) Nanostructures in Biodiagnostics. Chem Rev 105:1547-1562

Sadhu SK, Khatun A, Phattanawasin P, Ohtsuki T, Ishibashi M (2007) Lignan glycosides and flavonoids from Saraca asoca with antioxidant activity. J Nat Med 61:480-482

Sinha AK, Basu M, Pradhan M, Sarkar S, Pal T (2010) Fabrication of large-scale hierarchical $\mathrm{ZnO}$ hollow spheroids for hydrophobicity and photocatalysis. Chem A Euro J 16:7865-7874

Tanaka K (1999) Nanotechnology towards the 21st century. Thin Solid Films 341:120-125

Troiani HE, Camacho-Bragado A, Armendariz V, Gardea-Torresday JL, Yacaman MJ (2003) Synthesis of carbon onions by gold nanoparticles and electron irradiation. Chem Mater 15:10291031

Zhou XL, El Khoury, QuLT, Dai LM, Li Q (2007) A facile synthesis of aliphatic thiol surfactant with tunable length as a stabilizer of gold nanoparticles in organic solvents. J Colloid Interface Sci 308:381-384 